\title{
Population ageing and pension systems in \\ Latin America
}

\section{Jorge Bravo}

Population Division,

Latin American and

Caribbean Demographic

Centre (CELADE)

Economic Commission

for Latin America and the

Caribbean (ECLAC)

jbravo@eclac.cl
This paper will examine the effects of population ageing on the medium- and long-term evolution of pension systems in Latin America and the Caribbean. It is organized into six sections. After the introductory section, section II provides information on ageing and pension system trends in the Latin American countries, with some references to the international context. Section III gives indicators, data and methods of analysis, and examines the effects of ageing population structures and rising life expectancy on pension system variables: spending on pensions, the financial position, pension liabilities and the implicit rate of return; it also includes a critical analysis of the criteria that are generally used to evaluate the sustainability of unfunded systems. Next, section IV provides a more systematic introduction to the concept of and indicators used for implicit pension debt, gives estimates of the scale of the pension liabilities that have to be made explicit when the switch to a funded system takes place and analyses the effects of the age structure and adult mortality rates in the Latin American countries. Section V looks briefly at the fiscal transition costs that have to be coped with when this type of reform is applied and, lastly, section VI contains a summary and conclusions. 


\section{Introduction}

Over recent decades, the Latin America and Caribbean region has undergone substantial demographic changes that have altered the population base and the workings of the institutions that transfer resources between generational groups. One particular manifestation of these demographic changes, population ageing, is directly linked to developments in social security systems, and as the tendency towards ageing intensifies its effects will increase in scope and scale, as is shown very clearly by the historical experience of the more developed countries.

This is the essential standpoint of this paper, which examines the effects of population ageing on mediumand long-term developments in pension systems. This synthesis is based on studies carried out in recent years at CELADE and in collaboration with the Development Finance Unit of ECLAC that deal with the demographic and financial aspects of the region's pension system reforms.

First of all, the analysis focuses on the effects of changes in the age structure and in the mortality rates of the adult population on certain indicators of unfunded systems. It then deals with the transition from unfunded systems to funded ones, and in particular with the influence of demographic variables in determining pension liabilities and the fiscal costs of transition. In so doing, the paper brings together and analyses a variety of facts and results brought to light by applied research and uses medium- and long-term forecasts to consider how far these relationships may extend.

Every effort has been made to examine these issues systematically, but there are many important matters that are not addressed in this presentation. For example, it does not deal with general equilibrium relationships,

The original version of this article was prepared while the author was principal consultant to the ECLAC-CELADE/IDB programme ATN/TF-5827-RG attached to the Institut national d'études démographiques (INED) in Paris, France, from 15 December 1998 to 15 February 1999 under the international relations programme of that institute. It was revised at ECLAC and thanks are due for the valuable observations of Didier Blanchet, Georges Tapinos, Antoine Bommier, Andras Uthoff, Juan Chackiel, Carmelo Mesa-Lago, Mario Marcel and two anonymous readers from IDB. The author bears sole responsibility for any remaining errors or deficiencies. except for some references made in relation to associated topics. Many aspects that have given rise to major debates, such as the relative merits of funded and unfunded schemes, and of State-run systems and privately managed ones, are touched upon only insofar as they contribute to an understanding of the relationships with which this article is particularly concerned. ${ }^{1}$ The effects of gender differentiation, which become more important as populations age, are another relevant subject not addressed here (see Arenas, 2000; Cox, 1999 and Bravo, 1999).

The more specific approach taken here, however, does open the way to a clearer presentation and understanding of the effects of demography on different aspects of pension systems. Accordingly, the paper is organized as follows. Section II provides background information on ageing and pension system trends in the countries of Latin America, with some reference to the international situation. Section III explains the reasons for the analytical model approach used and examines the effects of ageing population structures and greater longevity on four important variables of unfunded systems: spending on pensions, the financial position of the system, pension liabilities and the implicit rate of return of the system. This section also includes a critical analysis of the criteria used to assess the sustainability of unfunded schemes.

Section IV provides a more systematic introduction to the concept of the implicit pension debt and the way this is measured, and gives estimates for the scale of the liabilities that have to be made explicit when the transition is made to a funded system. It also analyses the effects of the age structure and adult mortality in the Latin American countries. Section V briefly examines the transitional fiscal costs that have to be met when this type of reform is carried out, and section VI contains a summing up and closing remarks.

\footnotetext{
${ }^{1}$ A useful contribution to this debate would be a comprehensive analysis of the most important advantages and limitations of the different schemes, including the numerous demographic, economic and political issues involved and the development strategies of the countries where the assessment is to be applied. This is far beyond the scope of the present study.
} 


\section{II}

\section{Population ageing and}

\section{pension systems: Latin America}

in the international context

Having passed through the early stages in the demographic transition, in which child mortality fell and fertility was sharply reduced, the population of Latin America is beginning to age. Over-60s make up the fastest-growing population group in the region: their numbers, currently around 40 million, are expected to double within 20 years. The proportion of the population aged 60 and over is still modest by comparison with the more developed countries of the world: it now stands at just under $8 \%$ in Latin America, compared to about $16 \%$ in the United States, $20 \%$ in Europe and almost 23\% in Japan (United Nations, 1998). Nonetheless, mortality in the region has been falling substantially over the course of this century, and is now fairly low in many countries; average life expectancy at birth has now reached the 70 mark, and life expectancy at 60 is almost 20 years (ECLAC/CELADE, $1998)$ in the region as a whole. In virtually all the countries of the region, reductions in national fertility rates have tended to follow reductions in mortality after a relatively short time lag, in most cases less than two decades (Bravo, 1992). Taken all together, these trends imply that ageing, as measured either by the "old" proportion of the population or by the old-age dependency ratio, is going to accelerate over the coming decades, and is going to do so at a much faster rate than was seen in the populations where ageing is now most advanced. Changes in these indicators which took from six to ten decades to come about in the developed countries are expected to take only two to three decades in most of the Latin American countries. ${ }^{2}$

As is the case with almost all socio-economic and demographic variables in the region, there is great diversity between countries as regards ageing: some (for example Bolivia, Honduras and Nicaragua) still have fairly young age distributions and will continue to do so for many years to come. A number of countries

${ }^{2}$ For more extensive analyses of ageing tendencies in the region, see Chackiel (2000) and Villa and Rivadeneira (2000). are at intermediate stages in the demographic transition and are projected to age significantly over the next few decades (including the two most populous ones, Brazil and Mexico), while in a few countries ageing is already fairly advanced, such as Argentina, Uruguay and some of the Caribbean countries. In countries such as Chile, Costa Rica and Panama ageing is only slightly less advanced, with low mortality not yet being matched by such low fertility rates. Cuba is a special case, as in no other country of the region has fertility declined faster or more sharply since the 1960 s, so that in just over a decade the ageing process will be more advanced there than in any other country. Ageing also varies within countries, between socio-economic groups and by gender. As has been documented in detail elsewhere, the specific social context, and the particular sequence of events during the demographic transition, also vary from one country to the next (Guzmán, 1996 and CosioZavala, 1996). The different demographic contexts will be taken into account in the discussion that follows, to the extent that they affect ageing patterns.

As regards the formal public pension systems that are analysed here in relation to population ageing, these are not at all times and in all places the most important means of providing economic support to the elderly. Intergenerational transfers, effected through family/ community or market mechanisms (Sauvy, 1953 and Lee, 1995), have historically been important in both developing and developed countries, and still are. ${ }^{3}$ In Latin America, some countries began to institutionalize their pension systems in the early twentieth century (examples being Argentina, Chile and Uruguay), but

\footnotetext{
${ }^{3}$ The evidence reviewed by Lee (1995) indicates that in traditional societies intergenerational transfers are "downward" overall, i.e., they pass from the older members of the population to the younger ones. This also holds true for family transfers in developed countries today. It is the strong "upward" movement of transfers channelled through saving capital accumulation and the public sector (including pensions) that has produced the net upward direction of intergenerational transfers in more developed societies.
} 
most national systems became more comprehensive in the post-war period. Since their inception, these systems have expanded their coverage and brought major benefits to a significant proportion of the elderly population. However, they have also suffered from a number of problems. They have had difficulty in achieving the ideal of universal coverage, ensuring full and timely collection of contributions, protecting the real value of reserve funds and making the contribution and benefit adjustments that have become necessary as population structures have changed and systems have matured (Mesa-Lago, 1985 and Uthoff, 1997). These problems have built up over the years and have been compounded by the regional economic crisis of the 1980s, which brought administrative and financial shortcomings more clearly to light. These factors weighed heavily in the pension scheme assessments and proposals for reform that were made in that decade and put into effect in the 1990s. In the following sections we shall examine some of the reform issues from the point of view of population ageing and its implications for financing and intergenerational distribution.

In the Latin America region, as in the rest of the world, most public pension systems are unfunded and are backed by relatively small reserves. ${ }^{4}$ Public spending on pensions has grown steadily worldwide and now averages between $8 \%$ and $10 \%$ of GDP in the Organisation for Economic Co-operation and Development (OECD) and the countries of eastern Europe (World Bank, 1994 and Dumont, 1998). In many industrial countries, social security spending is one of the two or three biggest government expenditure items; in the United States, social security is now the biggest government programme, having overtaken defence in the early 1990s. Forecasts by OECD (Leibfritz and Roseveare, 1995) predict that over the twenty-first century pension payments could range from 5\% to $20 \%$ of GDP and that deficits could be from $0 \%$ to $10 \%$ of GDP, unless substantial adjustments are made over the coming years. The main factors influencing these forecasts are the long-term trend towards population ageing and the fluctuations predicted in the age structure of the population as a result of the baby boom in the early 1960s.

\footnotetext{
${ }^{4}$ A notable exception is the United States, where the important old age, sickness and death insurance (OASDI) fund will carry on growing for at least another decade to provide for the retirement of the large baby boom cohorts. There is considerable controversy, however, over the liquidity and real economic value of the assets making up this fund.
}

In Latin America, by contrast, the overall level of pension spending is similar to that of Asia, ${ }^{5}$ averaging around $2 \%$ to $3 \%$ of GDP. Comparison of this aggregate expenditure level with the ageing indicators referred to earlier shows that there is a large gap between the Latin American countries and the more developed regions and countries, whose ageing indicators are double or treble those of Latin America, but which spend four or five times as much on pensions as a proportion of GDP. We shall analyse these differences further in the following section.

Before turning to a more thorough evaluation of the effects of ageing, it is worth glancing at the global implications of this phenomenon in the coming decades. As figure 1 shows, the adult ageing process (measured by the old-age dependency ratio) is expected to accelerate in all regions of the world over the next few decades, even in Europe and North America where ageing is already well advanced. These changes are quite substantial: whereas in 1990 the old-age dependency ratio (population aged 65 and over in relation to the population aged 15 to 64 ) varied from $6 \%$ to $18 \%$ in different regions (the world average being $10 \%$ ), it is forecast that by 2030 all regions except Africa will have dependency ratios of between $16 \%$ and $35 \%$ (with a world average of $17 \%)^{6}$

The chart shows that the population of Latin America and the Caribbean will age faster than the average, as the old-age dependency ratio there is forecast to reach the world average in 2030, but starting from a below-average value (8\%) in 1990. By 2050 the Latin American ratio will have more than tripled to stand at around $27 \%$, around three percentage points above the world average. The strength of this projected trend is only surpassed by longer-term projections for the European and OECD countries, which show the greatest ageing effects on pension systems hitherto estimated (Roseveare and others, 1996 and Calot and Chesnais, 1997).

When these changes occur in situations where pension systems are maturing, and where there are

\footnotetext{
5 There are a number of differences between the two regions, however: in Asia, public systems are generally of more recent creation, and tend to cover a smaller proportion of the workforce and the elderly (Kinsella and Gist, 1995).

${ }^{6}$ A simple interpretation of this tendency in terms of pension system variables is that, simply as a result of population ageing, contribution rates would have to increase by around $70 \%$ over this period to prevent the financial position becoming worse than it was in 1990.
} 
FIGURE 1

World ageing outlook, by region, 1990-2050

(Population aged 65 and over/population aged 15 to 64)

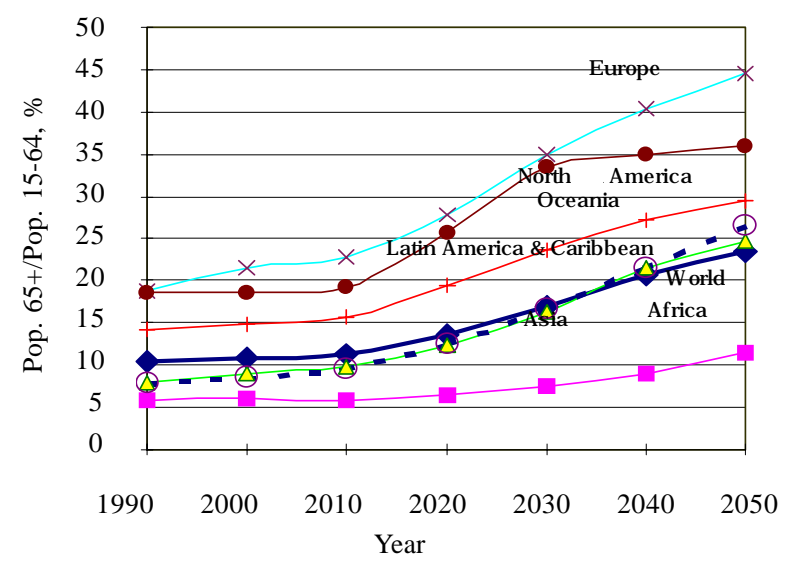

Source: United Nations (1998).

restrictions in the labour market that manifest themselves in high unemployment and low earnings growth, it is clear that these demographic trends will compound the adverse economic effects and the existing structural problems affecting public systems. As will be seen in the following sections, however, it is certainly wrong to interpret such difficulties as evidence that demographic trends are making these systems unsustainable, and that they are bound to lead to "bankruptcy" or an insurmountable crisis. Countries can supplement existing government-run unfunded systems with privately managed funded schemes or other (mixed) components, as some are now doing. However, numerous studies and different country experiences throughout the world make it plain ${ }^{7}$ that the demographic tendencies referred to here do not show that full funding is the sole or necessary solution, or the most desirable one, for the problems of pension schemes, as some observers believe. Most analysts now agree that thorough policy studies and assessments should consider different options, including varying degrees of public/private mix and funding, benefit- and contribution-defined schemes (Mesa-Lago, 1994; ECLAC, 1998; Thompson, 1999; Orszag and Stiglitz, 1999 and Holzmann, 1999), taking into account the different demographic, economic and political conditions obtaining in different countries.

The following sections of this paper will look at medium-term trends in these systems from a broad demographic point of view. First of all, a range of pension system indicators, and their relationship with ageing, will be analysed. Attention will then turn to unfunded pension liabilities and the influence on these of the population age structure and old-age mortality. The paper will then go on to consider the fiscal costs of unfunded-to-funded (U-F) transitions, after which it will conclude with some final remarks.

\section{III}

\section{Pension system indicators over the course of the ageing process}

\section{Indicators, data and methods of analysis}

Almost all pension system indicators are influenced by demographic variables, and particularly and most directly by population ageing. For this paper we have chosen four variables to illustrate our analysis of the effects of ageing on different aspects of unfunded pension systems: i) annual expenditure on pensions, expressed as a percentage of GDP; ii) the annual financial balance of the pension system, i.e. revenue minus outgoings, which can be expressed as a proportion of system revenue or of GDP; iii) the implicit pension liability, also known as implicit pension $\mathrm{debt}^{8}$ and iv) the implicit (or internal) rate of return of the system, as represented by flows of contribution payments and sums disbursed by way of pensions during the lifetime of a cohort. Appendices 1 and 2 give

\footnotetext{
${ }^{7}$ See, among many others, Blanchet (1990), ECLAC/CELADE (1996), Chand and Jaeger (1996), Conseil d'analyse économique (1998), Conte-Grand (1995), Reynaud, coord. (1998) and ECLAC (1998). ${ }^{8}$ As is explained in more detail in section IV below, there are a number of possible ways of measuring pension liabilities in unfunded systems. In this study we shall use the present value of the future pensions that will be received by pensioners and of the contributions already paid by the economically active population at a given point in time, expressed as percentages of GDP.
} 
more details about the concepts, measurements and data used to calculate these.

The most standard indicators, such as annual pensions spending or the financial balance of the system, are periodic measurements (i.e. annual flows) which can be used to quantify the burden of the pension system on the national economy, but which provide little information about the medium- or long-term financial sustainability of the system or its distributional performance, especially in different generational groups. These aspects are captured better, although still only partially and imperfectly, by other indicators that summarize contribution and benefit flows over the life cycle. Two of these are implicit pension debt and implicit system rate of return, which are analysed in the following sections. We have chosen $d$, the old-age dependency ratio, ${ }^{9}$ which from now on we shall simply call the dependency ratio, as the population ageing indicator to be used for analysing the pension system indicators selected. Historically, ageing of individuals or population cohorts, as measured by rising life expectancy, tends to precede and then overlap with changes in $d$, although the correlation between these two forms of ageing is not a strict one and their consequences for pension systems differ in nature and extent, as will be shown in the following sections.

Panel A of figure 2 shows observed pension expenditure values as a percentage of GDP, estimated on the basis of data compiled by ILO (1997) on national social security expenditure in the period 1991-1993. These estimates relate to old-age, survivors' and invalidity pensions in the public and private sectors and exclude transfers to other schemes. They are to be treated merely as an indication of magnitude, since the exact figure may vary depending on the specific measurement criteria being used. Again, no information is available for Brazil, Mexico, Peru and Uruguay, four very important countries in the region.

Nonetheless the data, plotted against the proportion of the population aged 60 and over, suggest a couple of things. Firstly, as had been predicted, the spending of many countries is of the order of $2 \%$ of GDP or less, among these being an appreciable number of Caribbean and Central American countries, Bolivia and Ecuador. The expenditure of the remaining countries ranges from a low of around 3\% of GDP in Colombia to a high of

\footnotetext{
${ }^{9}$ For the purposes of the present paper, this ratio will henceforth be between the population aged 60 and over and the population aged 20 to 59 .
}

FIGURE 2

Latin America and the Caribbean (selected countries): Pension system expenditure and financial balance, by degree of population ageing, 1990-1993

\section{A. Pension expenditure and population ageing}

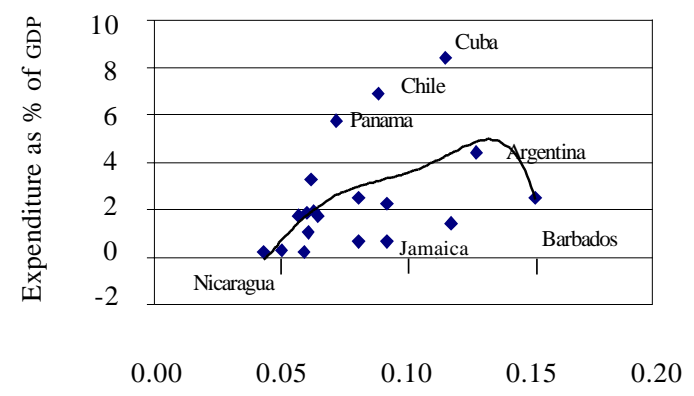

Proportion of the population aged 60 and over

B. Financial balance and old-age dependency ratio

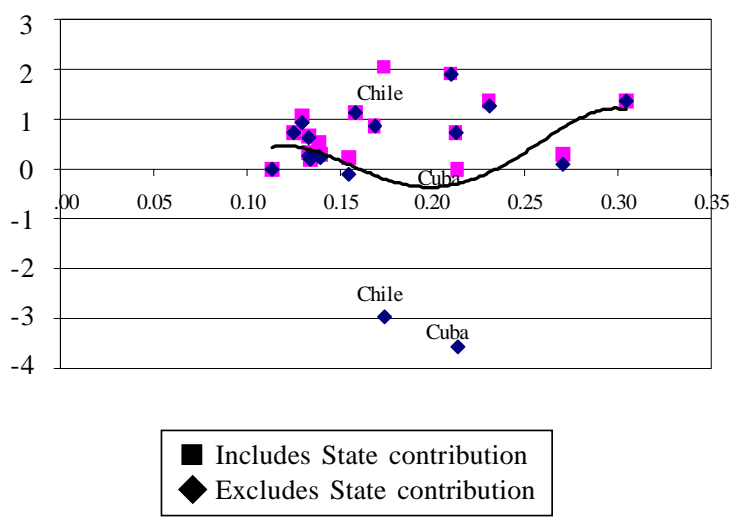

Source: Author's estimates based on ILO (1997), ECLAC/CELADE (1999) and United Nations (1999).

over $8 \%$ in Cuba, with countries such as Argentina, Chile and Panama being at an intermediate level. Taken all together, these data reveal spending levels that are low to medium by international standards. Secondly, although a number of the countries with high spending are in the medium to high ageing categories by regional standards, there is no obvious sign of a close relationship between the degree of ageing and pension expenditure. This partly reflects problems with the comparability of expenditure data, but also, and probably more importantly, differences in the population coverage of pension schemes, contribution and replacement rates, eligibility criteria and the degree of system maturity.

These two types of limitation make themselves felt to at least the same degree when the financial balance 
of the system is analysed. There are comparability problems not just with expenditure, as before, but also with revenue, which is affected by international differences in the way system components and programmes are defined and in accounting conventions, particularly as these relate to the treatment of transfers from other programmes and to State contributions net of the contribution made by the public sector as an employer (appendix 1). Bearing these caveats in mind, the estimates for the financial balance of pension systems given in panel $\mathrm{B}$ of figure 2 suggest that a surplus is the norm, particularly in countries whose schemes are of more recent creation. The exceptions are the small deficit of Panama and the more substantial ones of Chile and Cuba. ${ }^{10}$ These last two countries are special cases: the revenue and expenditure accounts of Chile are strongly affected by the transition deficit resulting from the move towards full funding, and those of Cuba by the fact that the State absorbs the primary imbalance, so that the country's system is precisely in balance when the State contribution is included. The transversal relationship observed between the demographic dependency ratio and the financial balance is even weaker than in the case of spending, for reasons similar to those already adduced.

To sum up, the data just analysed provide useful general information on the indicators and relationships we are concerned with, but offer rather limited possibilities for more detailed and specific study. ${ }^{11}$ For the purpose of isolating and analysing the effects of ageing on pension systems, a more viable and productive approach is to use individual country models, broken down by age, that take account of the key parameters of the system. The following model, which has had to leave out a number of the details and peculiarities of pension systems (appendix 2), gives rough orders of magnitude for the indicators we are concerned with, and not exact calculations. ${ }^{12}$ The drawbacks of simplification are compensated for by the possibility of studying a wider

\footnotetext{
${ }^{10}$ Argentina and Uruguay also had sizeable social security deficits in the late 1970s and early 1980s (Mesa-Lago, 1991, table 9).

${ }^{11}$ In theory, another approach would be to carry out longitudinal analyses on countries with reliable chronological series of spending and revenue data. This requires consistent, complete statistical series covering at least four or five decades so that substantial changes arise in the indicators of ageing, something that limits yet further the scope for carrying out this kind of analysis in the case of most Latin American countries.

12 The calculations are strictly valid if the rules of the system, labour force participation, coverage rates and the degree of compliance with contribution liabilities are constant in each country.
}

range of ageing levels (outside the range observed hitherto in Latin America) and examining other important system variables, such as pension liabilities and the system's internal rate of return, which are extremely difficult or impossible to calculate directly when existing data are the only basis used.

\section{Effects of ageing on the expenditure and financial balance of the system}

Figure 3 illustrates the general tendencies forecast for these two variables as the population ages. The figures shown assume fixed values for the contribution rate $(\mathrm{c}=12.2 \%)$, wages as a share of GDP $(\mathrm{s}=34.3 \%)$ and the number of workers covered by the pension system as a proportion of all waged workers $(k=0.76)$, these being the averages for the Latin American countries around 1990. In the case of the financial balance, it is further assumed that no debt or reserve fund capable of offsetting periodic imbalances has been set up; in other words, our definition of balance reflects the primary surplus or deficit.

Figure 3 isolates the demographic effect in the usual way by setting the value of other accompanying factors and examining the change in the indicators that concern us within a plausible range for our ageing variable, $d$. Four reference points are graphed for each system indicator. The first two points, from left to right, are obtained from the demographic profile (adult age structure and mortality schedule) of Nicaragua in 1990 and Uruguay in 1990, these being the countries that have the youngest and oldest age structures in the region, respectively. In addition, to provide an idea of the way pension system indicators may change over the longer term, the third point corresponds to the demographic profile of France in 1990 and the fourth one to the profile projected for France in 2050 (Dinh, 1995 and Meslé and Vallin, 1998).

Panel A of the chart shows the linear relationship between pension system spending and ageing (indexed by $d$ ), other things being equal, that is embedded in the model conditions. The values for the data confirm the fact, already documented in section II of this paper, that when systems cover a fraction of a demographically "young" working-age population, pension spending may be just $1 \%$ or $2 \%$ of GDP, but that this can reach levels of close to $10 \%$ when the country's population reaches an advanced state of ageing, even if coverage remains as incomplete as it is at present in Latin America as a whole (about half the workforce). Spending levels can be even higher in practice when coverage is wider 
FIGURE 3

Simulation of pension system expenditure and financial balance by degree of ageing, in accordance with the model conditions $^{\mathrm{a}}$

A. Ageing and pension expenditure

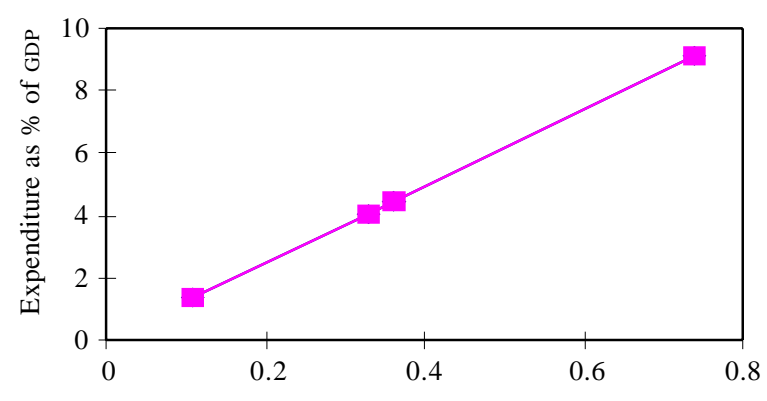

Dependency ratio (pop. 60+/pop. 20-59)

B. Ageing and financial balance of the pension system (\% of income)

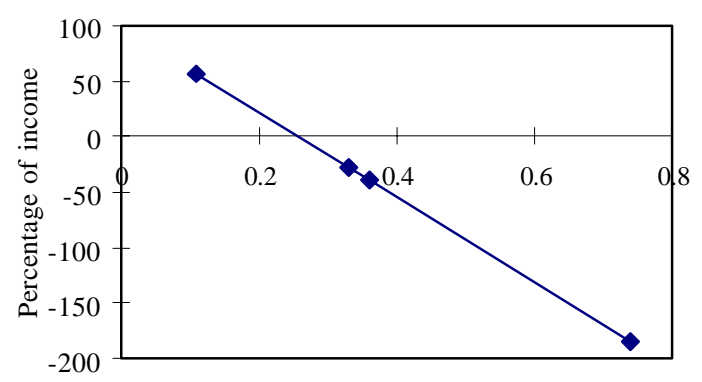

Dependency ratio (pop. 60+/pop. 20-59)

C. Ageing and financial balance of the pension system (\% of $G D P)$

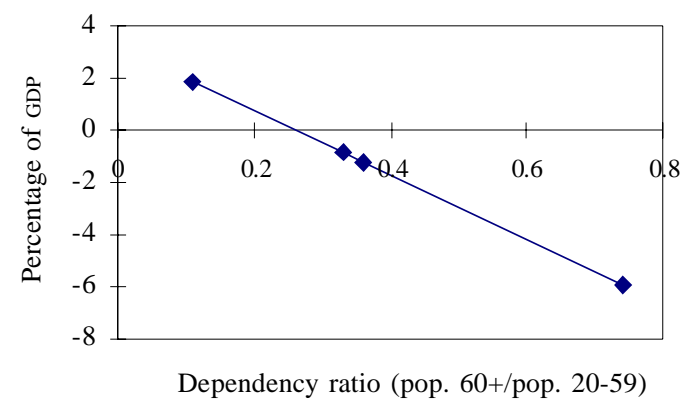

a As described in section III, part 1 . The suppositions and equations used in the model are given in appendix 2. The parameters used in this simulation are "typical" ones, i.e. averages for Latin American pension systems and labour markets, while demographic conditions are allowed to vary within the range given. From left to right, the points represent the demographic profiles of Nicaragua in 1990, Uruguay in 1990, France in 1990 and France in 2050. or universal: pension spending in Italy is already about $15 \%$ of GDP and, as has already been noted, it is expected to go even higher than this in some OECD countries over the twenty-first century. ${ }^{13}$

While expenditure levels give an indication of the weight that pension programmes have in the economy, a better idea of the aggregate financial performance of the system is obtained from the balance, i.e. the difference between the system's annual revenue from contributions and its yearly pension payments. Panels $\mathrm{B}$ and $\mathrm{C}$ of figure 3 show two possible variants of this indicator: the balance as a proportion of system revenue and as a percentage of GDP. Both are also linear functions of $d$, in accordance with the conditions of the model. These lines suggest that, if the system variables (contribution rates, replacement rates and membership conditions) are not adjusted, population ageing can turn a surplus in the initial balance when populations are "young" ( $d$ less than 0.3 ) into substantial deficits, which may amount to as much as twice system revenue, or $6 \%$ of GDP, when population ageing is very advanced ( $d$ of around 0.8 ), given constant parameters which are the averages for the Latin American systems. This theoretical possibility, however, has not hitherto come about in the region. In the maturer and more "aged" systems of the more developed countries, the system variables (contributions, benefit amounts or eligibility conditions) are usually adjusted before such extreme situations arise.

\section{Sustainability of unfunded systems and intergenerational equity}

It is not always easy to define what a "sustainable" level of pension spending or an "unsustainable" deficit level is, since in practice this involves many simultaneous variables. In public debate, political considerations may lead to a relatively modest current or projected deficit being described as excessive with a view to justifying reforms involving a change in the system, while substantial deficits may not be regarded as a serious problem if they can be financed by increasing public debt, which will have to be coped with by future governments and paid off by future generations of taxpayers.

But even if political considerations are left aside for analytical purposes, the definition of sustainability

\footnotetext{
13 A simulation for typical Latin American pension system parameters based on the present model (Bravo, 1999) shows that with universal coverage spending levels in the region would be roughly double those shown in panel A of figure 3 .
} 
is still complex, particularly when it is limited to the standard indices of the periodic system. For example, an extraordinarily high level of pension spending (as in Italy, for example) is chiefly a reflection of the fact that the country's population is currently one of the oldest in the world. It is very natural that, both at the individual level and in society as a whole, the resources used to finance consumption by the elderly should increase as people live longer and longer. This cannot in itself be regarded as an "unsustainable" tendency; insolvency will only occur if insufficient provision is made to finance this increased spending over a reasonably long period that is consistent with the time horizon over which the pension system contracts liabilities and pays out benefits. ${ }^{14}$

The financial balance (of the period) is more informative in this regard, but still falls short of providing a clear solvency test, since primary financial imbalances can arise simply as a result of the different degrees of maturity that systems have reached or of temporary economic fluctuations, which do not imply insolvency in the sense just indicated. When there are large, persistent deficits (such as the ones projected for a number of OECD countries over the twenty-first century, assuming all variables except ageing remain unchanged) it is more obvious that adjustments are needed, but even here a clear distinction needs to be drawn between the "sustainability" of continuing parameter values (contribution levels, benefit calculation methods, eligibility conditions), which can be changed, and the viability of the system's general design, which has more to do with its suitability for a particular type of development model and is more a function of economic policy considerations than of the degree of ageing in the population as such.

Full actuarial analyses that take account of present and projected system parameters are a more satisfactory way of assessing the solvency and the medium- to longterm sustainability of systems. Indeed, if there were certainty about the current values and future trend of the different system variables, the actuarial balance would be an excellent summary measure of solvency (in the medium term). Many developed country systems have well-established actuarial assessment practices. In most of the Latin American countries, unfortunately, analyses of this kind are not carried out consistently (see Mesa-Lago, 1985 and 1991), although it would

${ }^{14}$ Baldacci and Tuzi (1999) provide an interesting analysis of demographic and labour market changes and the sustainability of the Italian pension system. be a great help in establishing common ground for policy discussions if they were (Mesa-Lago, 2000). Nonetheless, uncertainty about the future, particularly in the medium to long term, means that in any specific instance these assessments have to be interpreted with caution, since the accuracy of the results depends directly on the validity of the assumptions made.

Policy analyses are making increasing use of stock/ lifetime summary measures of system accounts to examine the comparative medium- to long-term financial stance of the systems concerned. ${ }^{15}$ These are discussed in more detail in the following section. One of these stock measures is the implicit pension debt (or liability), i.e., the present value of unfunded pension system liabilities towards pensioners and active workers at a given point in time. This indicator, calculated in accordance with the model conditions, is graphed in panel A of figure 4 against our preferred index of ageing $d$. It can be seen that it rises in an almost linear fashion against the dependency ratio within the range given.

The implicit pension debt is a useful summary indicator and, as the following sections show in some detail, is essential for understanding and measuring the fiscal cost of closing an existing pay-as-you-go system. It does not however tell us directly whether a particular system is "sustainable" or not. As in the case of spending, the pension liability rises naturally as the system matures and expands its coverage and as the population ages. Again, if for example a large implicit debt can carry on being "rolled over" to future generations (as happens in a continuing pay-as-you-go system) under conditions acceptable to workers and pensioners, then there is not a strong case for deeming it unviable. ${ }^{16}$ Furthermore, it is possible for a low dependency system to have a small implicit debt and, at the same time, a significant permanent deficit, as demonstrated by the model estimates for El Salvador and Guatemala (not shown here). In fact, Nicaragua, a country with a low pension debt, had a modest operating deficit in the early 1990s. The opposite situation can also occur: countries with a high pension debt and a relatively aged population that can show sustained financial balance or even a budgetary surplus

\footnotetext{
${ }^{15}$ See Franco (1995) for a good critical discussion of the different indicators.

${ }^{16}$ From a macroeconomic point of view, a valid criterion, particularly for highly indebted countries with relatively mature systems, is the increase in public-sector liabilities (including those of the pension system). Chand and Jaeger (1996) provide an excellent discussion along these lines for a number of industrialized countries.
} 
FIGURE 4

Simulated values for implicit pension debt and implicit rate of return of the pension system, in accordance with the model conditions ${ }^{\mathrm{a}}$

A. Implicit pension debt and ageing

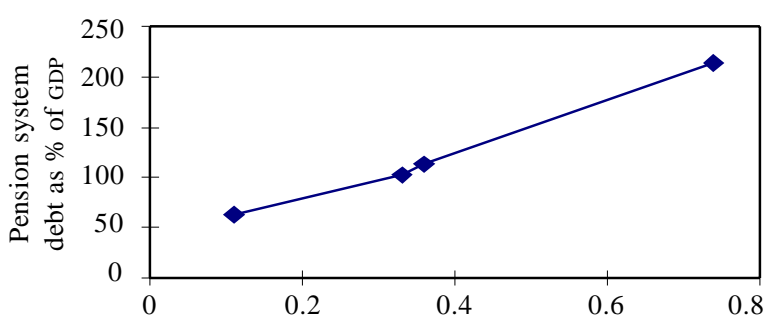

Dependency ratio (pop. 60+/pop. 20-59)

B. Pension system rate of return and ageing

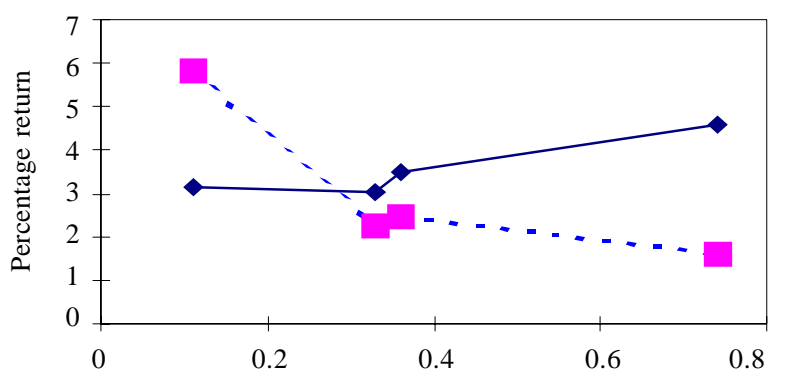

Dependency ratio (pop. 60+/pop. 20-59)

a As described in section III, part 1. The suppositions and equations used in the model are given in appendix 2. The parameters used in this simulation are "typical" ones, i.e. averages for Latin American pension systems and labour markets, while demographic conditions are allowed to vary within the range given. From left to right, the points represent the demographic profiles of Nicaragua in 1990, Uruguay in 1990, France in 1990 and France in 2050.

(for example, the model estimates for Chile and Uruguay). Costa Rica, a relatively high debt country, had an operating surplus in the early 1990s; a more extreme case is that of the United States, which has a large pension liability but a substantial periodic balance surplus. A number of other OECD countries have even greater pension liabilities but operate with modest deficits or balanced budgets.

In some cases, a more consistent diagnosis can be obtained when spending, the financial deficit and the pension debt are all substantial, as for example in Argentina and Uruguay during the 1980s. When all the indicators point in the same direction, the need to make major adjustments to the system becomes more obvious.
In many theoretical and real-world situations, though, the indicators referred to do not permit of an unambiguous interpretation, which supports the idea that there is no generally applicable rule to justify the need for one particular type of reform on the basis of ageing trends alone. ${ }^{17}$

Another way of approaching the problem is to ask how the system affects different generational groups. In fact, one increasingly widespread approach to determining the sustainability of public policy or a particular government programme, which is what we are concerned with here, is to consider that a system or policy suffers from intergenerational inequity if it provides benefits to current generations at the expense of the economic welfare of future ones. In extreme cases, a particular programme or policy may prove to be more absolutely unsustainable if it requires future generations to bear an excessively large net lifetime tax burden. An example of this situation is provided by Gokhale (1995), who uses generational accounts for the United States to calculate that if current government economic policies were continued, future generations would have to bear a net tax burden 35 percentage points higher than that borne by current generations, yielding the obviously inconceivable figure of $80 \%$ of lifetime income.

Panel B of figure 4 plots the implicit rate of return of the pension system (r), which reflects the net lifetime benefit of participating in the system for a given individual or cohort. What $\mathrm{r}$ measures is the excess proportionate present value that the individual or cohort obtains in pension benefits over and above the value of the contributions paid into the system over their working life, an indicator analogous to the one used to measure the rate of return on financial investments. ${ }^{18}$ As in the case of the variables plotted previously, this indicator is calculated in accordance with the general assumptions of our basic model, with two alternative scenarios now being considered: firstly, the case where the system variables remain constant throughout the ageing process and the general

\footnotetext{
${ }^{17}$ See Blanchet (1990 and 1998) for a fine, nuanced discussion of the relative merits of funded and unfunded systems under changing demographic conditions in a context of general balance, which refutes some common misconceptions about the subject.

${ }^{18}$ See Bravo (1996) for a more detailed discussion of the implicit rate of return and the way this is affected by different factors and policies. Related effects on lifetime wealth are studied in Auerbach and Kotlikoff (1987), Arrau (1991) and Cifuentes (1995) in the context of general-equilibrium, overlapping-generation models.
} 
government budget absorbs any imbalance that may arise in the pension system and, secondly, the case where the ratio between contributions and benefits is planned in such a way that it adjusts to changes in the demographic profile and financial balance is obtained at all times. Neither of these two functions of $d$ is strictly linear, for the reasons given below.

The first line shows that when the contributions/ benefits ratio remains constant, the greater adult longevity that occurs in the ageing process leads firstly to a slight fall in $\mathrm{r}$, then to a large increase. This happens because the greatest declines in adult mortality are obtained first for the "young adult" or working ages, while later declines mainly occur at more advanced (retirement) ages. This means that the ratio between the number of years lived as a pensioner and the number lived as a worker first remains constant or declines somewhat, then rises sharply.

The second line shows that if the contributions/ benefits ratio always stays at levels that produce financial balance, then the system rate of return declines rapidly with $d$, at least until "moderate" ageing levels are reached, after which it falls at a slower rate. The explanation is as follows. When the population ages in a balanced system, contributions have to be increased or benefits reduced. Given that the early stages of ageing in the adult population are primarily due to declining fertility -and not to survival to advanced ages- the adjustment in the contributions/benefits ratio is considerable by comparison with the modest improvements in adult survival rates. After $d=0.8$, the falls in $r$ become much smaller, as much of the change in $d$ is produced by increases in the ratio between the number of years lived at advanced ages and the number lived at young adult ages, and this has a positive effect on $r$ which largely offsets the negative effect of the necessary increase in the contributions/benefits ratio.

Which of these two scenarios -the one where contribution and replacement rates are fixed or the one that produces financial balance- is more "sustainable", in the sense of minimizing intergenerational inequity? The chart suggests that maintaining fixed rules in the system during the early stages of the ageing process (up to $d=0.3$, in figure 4 ) leads to a reasonably stable rate of return, while at the more advanced stages of the ageing process the financial balance rule would give smaller differences in the rate of return between cohorts. If the same data are interpreted from a slightly different point of view, it transpires that in the early stages of the process disproportionately large transfers would be made to the early cohorts if the system worked on the basis of financial balance, i.e., if all revenue were transferred automatically in the form of pensions, without considering the contributions made by the pensioners. The chart also illustrates the risk of providing excessively generous benefits to the later cohorts, since the system will go into a state of chronic underfunding (after $d=0.3$, in the chart) if the benefits/ contributions ratio does not adjust to a more elderly demographic context.

Consequently, in the long-term ageing process the following sequence of policies could prevent large differences arising in the rate of return obtained by different cohorts: i) fixing both contribution and benefit rates during the early stages of the ageing process and ii) when ageing is further advanced, changing over to the financial equilibrium rule, which would ensure greater intergenerational equity at this stage. The first part of this sequence -offering defined benefits in exchange for more or less defined contributions- has in fact been the rule traditionally followed by many countries; most current systems are still benefit-defined. As more recent experience shows, however, switching to the second stage rule ("financial balance") has proved more problematic, since although fiscal constraints make the changeover virtually unavoidable, this entails a loss (by comparison with the no-change scenario) for present generations of workers, to which there is often political resistance. ${ }^{19}$ If today's cohorts of workers are successful in holding out against change and resisting direct or indirect financing, however, the current deficit will be transferred to future generations, which means that intergenerational equity will be impaired.

Given this situation, two basic approaches can be taken to achieving financial balance. The most common and traditional one, expressed in terms of a definedbenefit logic and terminology, involves "parametric" changes or reforms in which contributions are changed, benefits adjusted or eligibility conditions made more stringent. The second approach consists in making explicit the dual objective of financial solvency and intergenerational equity and designing the system in a way that can accommodate both. One approach of this kind, known as the "notional contribution" scheme,

\footnotetext{
19 The changeover to the financial balance rule can be facilitated enormously if the surplus generated since the system began is suitably invested and is used to cover deficits when the system matures. This, indeed, is sensible advice for countries that have young populations and set up their systems recently, but it comes too late for those that have already spent the surplus or have let the real value of reserves be eroded by negative rates of return.
} 
has been applied in Sweden, Italy and Latvia, and is under consideration in other eastern European countries (Holzmann, 1997 and ECLAC, 1998). Essentially, this is a contribution-defined scheme financed mainly on the pay-as-you-go model, with only moderate reserves being built up to smooth over any temporary imbalances. Under such schemes individual records are created (analogous to the "accounts" of funded systems) and these accrue contributions plus interest at a rate determined by the annual growth in total wages. By comparison with other unfunded schemes, this kind of system has the merits of actuarial fairness, a greater likelihood of financial balance being maintained in the medium to long term, and less intergenerational inequity. In the region it is worth noting the case of Brazil, the country which is moving most clearly in this direction (Pinheiro and Vieira, 2000 and Uthoff, 1999).

From the demographic point of view, this type of system has the advantage of adjusting endogenously to changes in old-age mortality and of providing reasonable protection against age structure or labour market fluctuations. In an uncertain world, contribution-defined unfunded systems such as this tend to improve intergenerational risk sharing and to increase expected lifetime welfare (Thogersen, 1998). Of course, the system is not immune to potential risks, ${ }^{20}$ but these seem to be smaller than those affecting traditional benefit-defined systems or fully funded schemes. Proper actuarial monitoring is also essential to these schemes, in order to avoid imbalances lasting for extended periods. ${ }^{21}$

\section{IV}

\section{Implicit pension debt: concept and measures}

As has already been mentioned, the focus of public policy debate over pension systems is gradually shifting from short-term financial performance (current spending or deficit/surplus levels) to the medium- to long-term financial stance. This is especially true of the more developed countries, where population ageing began many decades ago and the process is far more advanced than in the less developed regions. In Latin America, a number of recent analyses have used medium-term projections that incorporate demographic trends in a more or less detailed way, among them being studies on Argentina, Chile, Colombia, Mexico and Uruguay (see Mesa-Lago, 2000, for a critical review of these) and on Brazil (Uthoff, 1999), in response to policy concerns that will be discussed later on. Some of these look explicitly at the notion of implicit pension debt.

One type of synthetic measure used in recent studies is "pension system liability", a stock measure that refers to the present value of liabilities towards those participating in the system (Van der Noord and Herd, 1994; Franco, 1995; Holzmann, 1997 and Vernière, 1997a). This type of indicator is based on the idea that in unfunded systems there is an implicit contract whereby the State, in return for workers' contributions, undertakes to pay the pensions of retired cohorts out of the contributions collected from the following (working-age) generation. In this case, it is logical to calculate the discounted (present) value of revenue and payment streams for a given point or period of time and number of cohorts. In the more developed countries where ageing is more advanced, the incentive for studying these liabilities is the general desire to evaluate the financial situation of the Government in the medium to long term (including spending, deficit and public debt levels) in the light of the current and projected degree of population ageing, which is affected by long-term tendencies and by the imminent effects of the baby boom which took place in those countries around four decades ago.

Some observers interpret the request made by Great Britain to the European Commission for the liabilities of unfunded social security systems to be included among the criteria for joining the single currency as a reflection

\footnotetext{
${ }^{20}$ Particularly the risks of low or negative returns from investment of the (relatively small) reserves and of contingent political pressure to follow the benefit formula for pensions, which may be perceived as giving a low wage replacement rate, especially during periods of high wage growth.

${ }^{21}$ See Valdés-Prieto (1999) for an analysis of the characteristics of these schemes and some of the problems that can affect them.
} 
of the concern that, because the liabilities of the public system in the United Kingdom are smaller than in the other countries of the European Union, there was the risk of British taxpayers having to finance the liabilities of other countries or be penalized with higher interest rates to defray these liabilities (Vernière, 1997a, p. 2). In the United States, the emphasis is more on how government expenditure as a whole (including pensions and public health programmes) can be sustained when the baby boom generations retire, without severe consequences for the public finances and for intergenerational distribution. Again, more recently, the implicit liabilities involved and the cost of liquidating them emerged as an important consideration in the proposals for social security reform discussed during the 2000 United States presidential election campaign. In Latin America, interest is fairly recent as well, and the difference in the demographic context means that it is driven by concern not so much over population ageing as over the fiscal burden that this type of government expenditure may represent now and in the near future, against a background of budgetary reforms and constraints. This is the issue that will be dealt with next.

\section{Definition and measurement}

A variety of terms and specifications, with slightly different meanings and uses, are employed for the concept of implicit pension debt (or liabilities) (Holzmann, 1997 and Van der Noord and Herd, 1994). Three main definitions are: i) liabilities accrued to date, which represent the present value of pensions to be paid, considering only the rights accrued by workers and pensioners at a given moment and ignoring future contributions and rights not yet accrued; ii) closed system obligations, comprising liabilities towards all current workers and pensioners, including their future contributions and the rights that will accrue to them in future; and iii) open system liabilities, which also include contributions and rights that will accrue to new entrants to the labour force.

The most relevant definition for calculating U-F transition costs is of the first type. Which of the variants is used will depend on the reform scenario being considered: whether the changeover to a funded system is partial or total, whether it is voluntary or compulsory for different generations of workers (present and future), whether it is immediate or gradual, etc. In the discussion that follows, which is largely based on studies carried out by the author in collaboration with Andras Uthoff (Uthoff and Bravo, 1998 and Bravo and Uthoff, 1999), we shall use a definition that takes into account the future flow of pensions accrued by current pensioners, plus compensation of contributions to date for all those currently in the labour force. This definition departs slightly from the standard "accrued to date" specification: the first component is different in that it provides for reimbursement of past contributions instead of pension rights. The two measures should give similar figures but may not coincide closely in all cases.

The policy context, very briefly, is as follows. We know that recent reforms in Latin America have included adjustment of eligibility conditions and benefits and, in several cases, inclusion of at least one contribution and benefit funding component. These cases include the early reform in Chile in 1981 which, like those of Mexico (1995), Bolivia (1996) and El Salvador (1997) meant a complete switch from benefit-defined pay-as-you-go State systems to privately managed, fully funded individual contribution-defined schemes. Other reforms have retained a pay-as-you-go component by establishing mixed ("multipillar") or parallel systems, examples being those of Peru (1992), Argentina (1993), Colombia (1993) and Uruguay (1995).

The funding component is supposed to lighten the financial burden that pay-as-you-go systems place on the State budget in the context of the demographic and labour market trends referred to, to stimulate greater efficiency in the management of the system, to bring about higher national saving and investment and to promote the development of financial markets, where the pension funds are invested. The evidence for all these benefits is mixed, partly because in many countries that reformed only a few years ago it is too soon to tell. In the early case of Chile, the growth and development of financial markets and the corresponding regulatory framework are manifest, although it is not clear whether funding has led to substantial increases in national saving or productive investment (Uthoff, 1997) or whether it has helped to reduce management fees, which still amount to over $20 \%$ of contributions. ${ }^{22}$ Several models suggest or predict long-term aggregate income and welfare benefits from U-F reforms (see Schmidt-Hebbel, 1997 and Valdés-Prieto, ed., 1997, and references therein), but it seems too early to evaluate this potentially important effect in most reform countries.

\footnotetext{
22 Recent data (presented in Mesa-Lago, 2000, table 6) imply that management fees vary widely, from about $4 \%$ of contributions in Bolivia to over 30\% in Argentina. See Valdés-Prieto (1999) for a more detailed analysis of fees and the difficulties involved in making rigorous comparisons between countries and firms.
} 
Furthermore, what is of specific interest to this section, U-F reforms do not necessarily lighten the fiscal burden in the short and medium term. On the contrary, recent data reported by ECLAC (1998) and the analysis in this paper suggest that this transition actually generates large fiscal liabilities which have to be met by present and future generations of workers. These costs arise because the transition makes it necessary to recognize explicitly and pay off some or all of the implicit social security debt, while the contributions of those switching to the funded scheme cease to be received as income.

In the following sections, we shall seek to measure the size of the implicit pension debt and work out the associated fiscal costs using a simple model and the information available on demographic variables, the labour market and the pension system, and we shall analyse the factors and results for the Latin American countries considered.

\section{Liability that has to be made explicit when the system is changed}

The basic scenario envisaged is one in which an unfunded State system is completely replaced by a privately run fully funded system. In this case, the liabilities ("debt" owed by the Government for pensions), calculated at proper actuarial values, are represented by the present value of the pensions accrued and to be accrued in future years by all the pensioners in the old unfunded system, plus the present value of the contributions of affiliated workers who are active at the time of the reform. ${ }^{23}$ To measure these liabilities directly and accurately, it would be necessary to have full, detailed chronological series of the age profiles of labour force participation, employment, coverage and compliance rates and earnings for, let us say, the last 40 years. Since this ideal database is not available in any Latin American country, we have developed a model that is able to provide a reasonable estimate using more widely available demographic, labour market and macroeconomic data.

The calculations make use of several highly simplifying assumptions, the most important of which are: i) an unfunded pension scheme has been in existence since 1950; ii) the overall system coverage

\footnotetext{
${ }^{23}$ A natural alternative definition of this last component, that of pension rights accrued to date by those who are active at the time of the reform, is theoretically less well defined and empirically less tractable.
}

rate has remained constant at the level of 1985 or thereabouts (an intermediate point in time between 1950 and 2020, the end of our projection period); iii) tax and replacement rates are the same as they were at the beginning of the 1980s (Mesa-Lago, 1991) and iv) the contributions of all the cohorts concerned begin at the age of 20 and continue uninterruptedly until they retire at 60 . The full set of assumptions and the derivation of the equations that follow are given in Bravo and Uthoff (1999). Using this simplified framework, it is possible to obtain estimates of the pension debt for a fairly large number of Latin American countries.

Taking these assumptions, pension liabilities towards the economically active population $(D a)$ can be expressed, as a proportion of GDP, as follows:

$$
D a=c \cdot s \cdot k \cdot A a
$$

where $c=$ contribution rate (expressed as a percentage of earnings); $s=$ the wage mass as a share of GDP; $k=$ ratio between the number of workers enrolled in the system (covered) and the total number of wage earners; $A a=$ readjusted average of the number of years for which the active population has been contributing.

In the same way, the debt owed to those who have already retired $(D r)$ is expressed as:

$$
D r=r \cdot s \cdot k \cdot d \cdot A r
$$

where $r=$ replacement rate (percentage of wages); $d=$ dependency ratio of the unfunded system (retirement-age population/working-age population); $A r=$ readjusted average of the expected number of years of retirement per currently retired person, and the other variables are as already defined. Both $A a$ and $A r$ are weighted readjusted averages, where weighting is by the number of people in the age groups concerned.

The estimates derived from this model are shown in figure 5; they are valid for our basic special case, where the discount rate is assumed to be equal to the rate of wage growth. ${ }^{24}$ This chart shows that the implicit pension debt is substantial in most of the Latin American countries, even some where the population is young and the coverage of the system low, such as the Dominican Republic, Ecuador and Honduras. The pension debt is substantial (over 20\% of GDP) in most of the countries and extremely high (over 200\% of GDP) in those with older populations or systems with high coverage such as Argentina, Brazil and Uruguay.

\footnotetext{
${ }^{24}$ The consequences of this assumption are dealt with in section V.
} 
FIGURE 5

Latin America and the Caribbean: Implicit pension debt (Percentage of GDP)

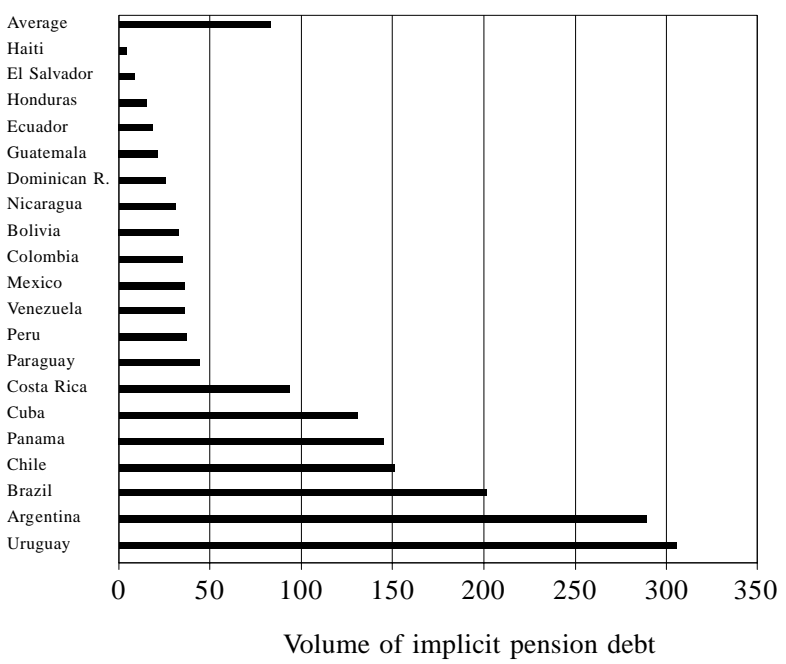

Source: ECLAC (1998), for the base situation where the discount rate equals the rate of wage growth.

By comparison, the level of pension liabilities in more developed and older countries is higher on average (of the order of $170 \%$ of GDP) than in the countries of the Latin America region, but varies less between countries, ranging from an estimated low of $113 \%$ in the United States to a high of $242 \%$ in Italy (Van der Noord and Herd, 1993).

It is interesting to note that in most of the countries for which information is available the implicit pension debt is not only large but, in many cases, is several times greater than the official public debt. Current estimates of pension debt put it at around a third of official public debt in Ecuador, one to two times the public debt in Colombia, Peru and Venezuela, more than four times the official government debt in Brazil and between 8 and 11 times the public debt in Argentina, Chile and Uruguay. These latter ratios also seem very large compared with those found in the more developed countries with older populations; for example, the implicit pension liabilities of France, Germany, Italy and the United Kingdom range from twice to four times their respective official public debts. ${ }^{25}$

${ }^{25}$ The public debt figures (as a percentage of GDP) for the Latin American countries are for around 1995 (El Mercurio, 1997). The pension debt estimates for the OECD countries are for rights accrued to date; the data sources are Van der Noord and Herd (1994) and, for public debt as a percentage of GDP, Le Monde-Économie (1999, p. 5).
Although several of the model's assumptions are crude and are valid only as an initial approximation, the estimates it produces, when calculated using the same basic data and parameter values, turn out to be reasonably close to other estimates based on alternative procedures. For example, Schmidt-Hebbel (1995), using a different method (the present value of projected deficits resulting from reform) and different parameters, places the implicit Colombian pension debt within a range of $59.2 \%$ to $88.1 \%$ of GDP, whereas our estimate (based on pre-reform parameters) is only $34.8 \%$. However, if we use the same parameters as the study cited, we obtain an estimate of $62.5 \%$, which falls within the lower end of its range of estimates. Our estimate of the Chilean pension debt, at $131 \%$ of GDP, is not far from the $126 \%$ figure given in Schmidt-Hebbel (1996, table 3.8). Our estimate for Brazil, at $201.6 \%$ of GDP, is within the range of estimates provided by other studies, which vary from $188 \%$ to $255 \%$ of GDP, depending on the assumptions made (Government of Brazil, 1998). As a final example, a calculation for France based on the present model yields an implicit debt of $224 \%$ of GDP, which is not far from the OECD estimate of $216 \%$. Mesa-Lago (2000) refers to other estimates calculated using different methods, noting that they are not strictly comparable with the ones presented here.

\section{Effects of the age structure and mortality patterns}

Demographic variables (basically the population age structure and old-age mortality) affect the size of the debt although, as will be shown shortly, their impact is not as large as that of other (pension system and labour market) variables. The population age structure is represented directly in the system's "dependency ratio" ( $d=$ old-age population over main working-age population), but it also enters into the calculation of the average number of contributing years of the active population $(A a)$ and that of the expected number of retirement years per currently retired person $(A r)$. In the latter case, old-age mortality conditions determine the expected number of years of life remaining to each of the cohorts currently of retirement age. ${ }^{26}$

\footnotetext{
${ }^{26}$ By construction, the value of $d$ is higher the more aged the population and the lower the mortality level. The value of $A a$ is higher the more aged the population, since there are more people at ages that have accrued more years of contributions. Ar, however, may be higher or lower in more aged, lower mortality settings, since lower mortality implies higher life expectancy at most (or all) adult ages but a more aged population structure means that younger pensioners
} 
To illustrate the magnitude of the demographic effects we replaced the average values for the Latin American countries with extreme national ageing and mortality values. More specifically, we first constructed a "benchmark" vector of indicators, defined as the mean value of each of the intervening variables, and estimated a benchmark debt stock. Then the debt was recalculated using the highest and the lowest old-age mortality levels (those of Bolivia and Costa Rica, respectively) and the youngest and oldest national age structures (those of Nicaragua and Uruguay, respectively).

Figure 6 gives the results. They suggest that oldage mortality has a very small effect on the size of the debt: factoring in Bolivia's high mortality rate instead of the "average" pattern for Latin America yields a pension debt only a few percentage points lower. It hardly makes any difference if Costa Rica's low oldage mortality is used instead. This result is largely due to the fact that in the region old-age mortality does not vary as much in absolute terms (which is what matters for the pension debt) as general mortality does: in the early 1990s, life expectancy at birth was about 68.6 for Latin America, 76.3 in Costa Rica and 59.3 in Bolivia (a difference of about 17 years between the lowest and highest), while life expectancy at age 60 was about 18.9 for Latin America, 19.5 in Costa Rica and 15.2 in Bolivia, a spread of only 4.3 years. Also, old-age mortality only affects that part of the debt that is "owed" to pensioners, which is the smallest of the two components of total pension debt in almost all the Latin American countries.

The population age structure plays a much more substantial role: using Nicaragua's age distribution instead of that of Latin America as a whole yields a pension debt more than nine percentage points smaller, while if the more aged structure of Uruguay is used the debt goes up by more than 40 percentage points. A more realistic comparison is between the last two bars of figure 6 , where the overall demographic configurations (age distribution and old-age mortality) of Nicaragua and Uruguay are contrasted, which gives a result almost identical to the previous one: a difference in the debt stock of about $40 \%$.

(who have a greater life expectancy) account for a smaller proportion of the population. Therefore, the resultant value of $A r$, as well as the final "demographic" effect on the stock of debt, depends on the particular combination of age structure and mortality at older ages in each country. As is shown in Bravo and Uthoff (1999), the positive ageing effect (which operates through $A a$ and $d$ ) tends to prevail over the ambiguous interaction between mortality at older ages and population ageing that operates through $A r$.
FIGURE 6

Pension debt under different demographic conditions ${ }^{a}$

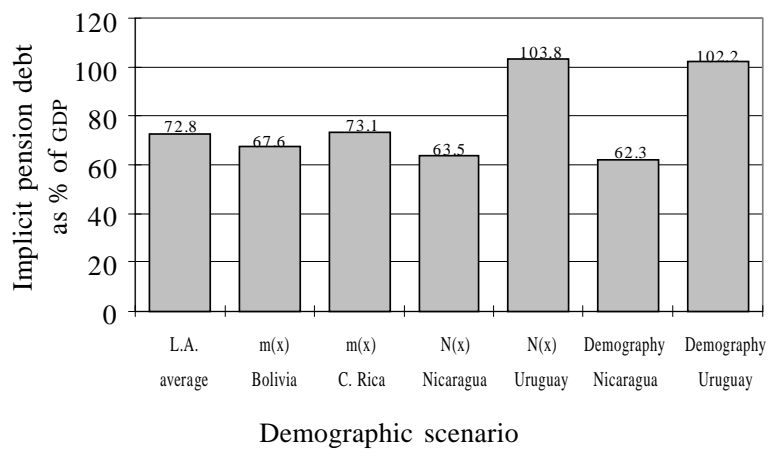

Source: Bravo and Uthoff (1999).

a $N(x)$ stands for the population age distribution and $m(x)$ for age-specific mortality.

It is important to note here that changes in other pension system and labour market factors have an even greater potential to affect the debt stock: if Nicaragua had Argentina's age structure its implicit debt would increase by more than $50 \%$, but it would almost double if Nicaragua had Argentina's population coverage and more than quadruple if it had Argentina's social security tax rate (Uthoff and Bravo, 1998).

The potential demographic effect, however, is at least as big a factor in the debt as some macroeconomic/ policy variables. One such variable is the discount rate used by governments to express past contributions and future benefits in common present values. For this discount rate to have an effect comparable to that of the population age structure, it would have to be more than $2 \%$ higher than the rate of wage growth.

When assessing medium-term fiscal obligations, it is useful to project the implicit debt to some future date (as was done for France, for example, by Vernière, 1997b). When this is done the corresponding estimate of the longitudinal ageing effect is quite robust since, although subject to some uncertainty, medium-term demographic changes are more predictable than, for example, interest rates or future economic growth. In particular, the fact that changes in the old-age dependency ratio up to 20 or 25 years ahead depend almost entirely on mortality patterns, which change only gradually over time, means that the projected trend can be regarded as fairly reliable. 


\section{$\mathrm{V}$}

\section{The fiscal costs of transition}

The extent to which the pension debt in any given country is "manageable" can be best appreciated by examining the annual fiscal outlay it entails. This fiscal cost depends on the size of the debt and also on other key macroeconomic and policy variables such as the GDP growth rate, the rate of interest paid on the public debt, the financing mechanisms used and other specific aspects of the reform.

Figure 7 illustrates the scale of the annual fiscal costs that would be involved were the whole implicit pension debt to be paid off over a period of 40 years (which is roughly the time it would take to complete the transition to the reformed pension system), given an annual GDP growth rate of around $4 \%$ and different assumptions regarding $\mathrm{D}$, the difference between the discount rate $(i)$ and the rate of wage growth (s).
This chart yields a similar reading to figure 6: the annual fiscal costs appear to be small to "manageable" (under $1.5 \%$ of GDP per year) in the countries in the "low" and "very low" debt groups; they are quite substantial -from $1.4 \%$ to $6.7 \%$ of GDP- in the "high" debt group (Chile, Costa Rica, Cuba and Panama); and they seem to be overly high for Argentina and Uruguay, as these two countries would need to make a financial effort equivalent to $6 \%$ to $13 \%$ of GDP (depending on assumptions) over a period of 40 years to pay off the full U-F transition costs. The estimates given are if anything conservative, as the supposed standard of dynamic efficiency in growth models implies an interest rate higher than total wage growth, so that $i$ is substantially higher than the rate of wage growth. It should be noted that the fiscal costs (as a proportion of

FIGURE 7

Latin America: Annual fiscal cost of transition over $\mathbf{4 0}$ years, by different values of delta ${ }^{\mathrm{a}}$

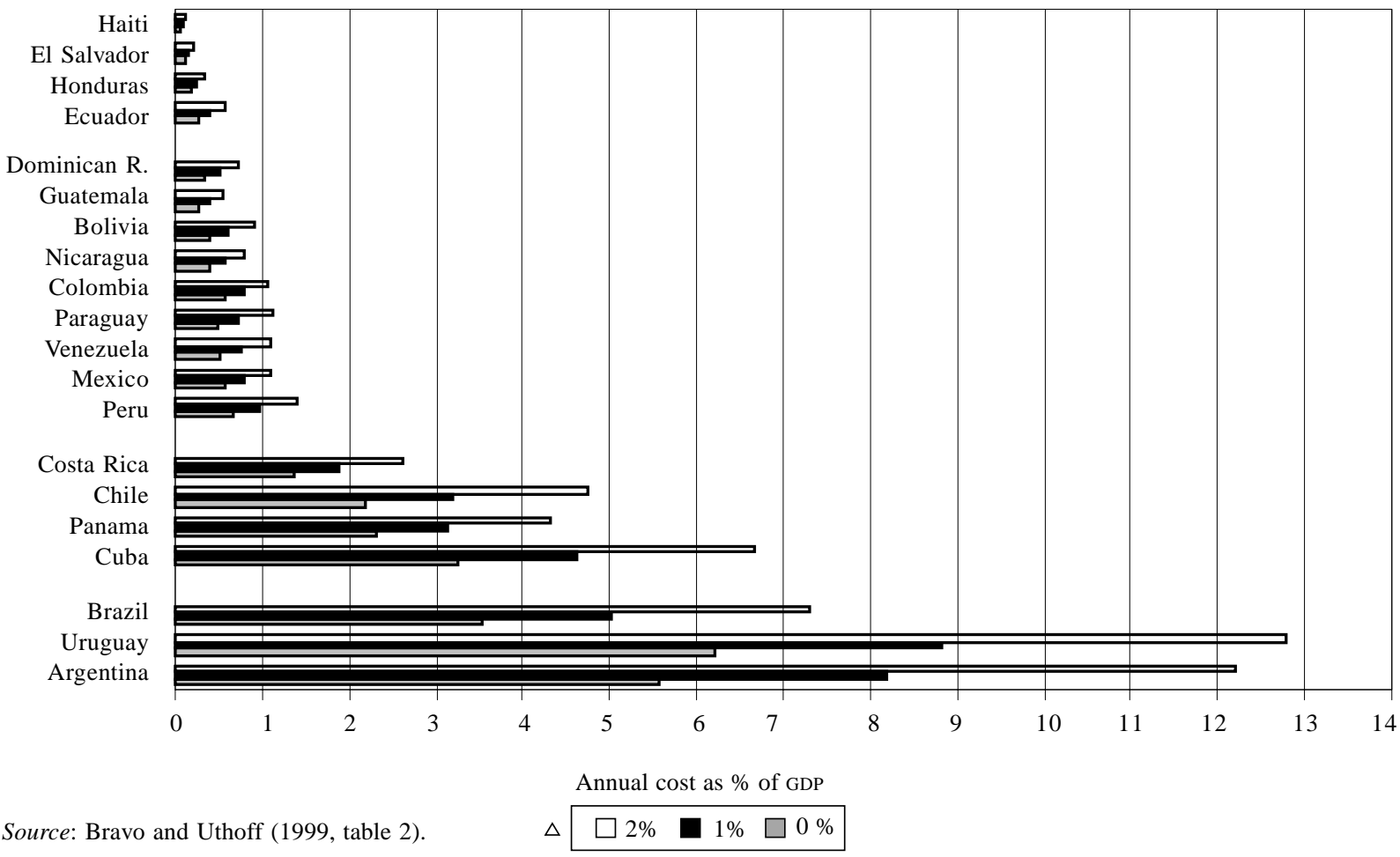

a Delta is the difference between the discount rate and the rate of wage growth. 
GDP) do not vary significantly with the level of GDP growth. What matters most is the difference between this growth rate and the discount (or interest) rate: a discount rate $2 \%$ higher than GDP growth means that in many cases the fiscal costs are more than double what they would be in a situation where $i=\sigma$.

These figures, which are for the average over a 40 year period, give a useful idea of the scale of costs involved. In actual transitions the fiscal costs vary over time, depending on the arrangements made for payment of the pension debt and the financing mechanisms used. ${ }^{27}$ In particular, extending the period over which the debt is paid (for example by setting periodic compensation as in Argentina and Bolivia, as opposed to the lump-sum "bond" used in Chile and Colombia) can achieve some reduction in the annual fiscal cost in situations where the discount rate $(i)$ is greater than the economic growth rate $(g)$. However, such reductions are not as dramatic as might be assumed: if $i$ exceeded $g$ by two percentage points, and the payment period were extended from 40 to 60 years (assuming this were feasible), the annual cost of repaying a debt of $D=$ $100 \%$ of GDP would fall from $3.7 \%$ to $2.9 \%$ of GDP, and if it were extended to 80 years the annual cost would still be $2.5 \%$ a year. $^{28}$

Bravo and Uthoff (1999) discuss the observed and projected trajectories of the transitional deficits of Argentina, Bolivia and Chile according to the abovementioned model, noting the constraints these would place on the overall government budget and the risk of default on the entitlements accrued by workers and pensioners in the pension system. More detailed accounts of the cases of Brazil and Chile are given in Uthoff (1999) and Arenas (2000), respectively, showing how the timescale over which liabilities are amortized

\footnotetext{
27 Two main financing mechanisms are (current) taxes and the issuance of new official public debt (i.e. future taxes). The financing mix affects both the amortization programme and the way the transitional costs are distributed between present and future generations of taxpayers. These intergenerational distribution effects are important, but will not be discussed here in any detail. See Arrau (1991), Schmidt-Hebbel (1995), Cifuentes (1995) and Valdés-Prieto, ed. (1997).

${ }^{28}$ After about 90 years, no further reductions would be obtained in the annual fiscal cost; the reductions diminish and the time after which no further reductions occur is shorter the larger the difference $i-g$ is.
}

depends on the present and projected age and sex distribution of the active and retired population. In the simulations for Brazil, the most salient features are the greater relative importance of pensions being paid under the old system during the early stages of the transition and the subsequent predominance of the State guarantees for the non-contributory system and the "recognition bonds", the latter being provided to the relatively large working-age cohorts. In the case of Chile, perhaps the most significant features are the growing relative importance of women and the guaranteed minimum and "welfare" pensions over the medium to long term, which are likely to impose a large fiscal liability for pension funding well beyond the transition period.

Two final observations should be made regarding the practical policy-making process. Firstly, the level of debt and the payment schedule are not absolute givens, and countries can and have sought ways to make the fiscal costs more bearable (ECLAC, 1998 and Queisser, 1998). Many countries in Latin America have made only a partial switch to funding (this is the case with all the recent reforms, except those of Bolivia, Chile and Mexico), something that is particularly important for countries with mature, high-coverage pension systems and aged populations, such as Argentina and Uruguay. Changes to benefits and eligibility conditions, timed to coincide with the switch to funding, have also been made with a view to reducing fiscal obligations, and other stipulations have been introduced to the same end (Holzmann, 1997; ECLAC, 1998 and Mesa-Lago, 2000). Secondly, the overall macroeconomic and fiscal environment is crucial for a country's prospects of absorbing the transition costs. For example, implementation of the Chilean reform (which involves a complete switch) has been made possible by a very positive macroeconomic performance to date and by vigorous implementation of the necessary changes to the regulatory framework for the financial market (Arrau, 1994). Even so, it has required great fiscal discipline. All the reforming countries in the region have made efforts in these directions, with differing degrees of strain on their budgets and with different balances being struck between easing the fiscal burden and reducing the benefits provided to those in the system (Bravo and Uthoff, 1999 and Mesa-Lago, 2000). 


\section{VI}

\section{Summary and conclusions}

After decades of declining demographic indices, the population of Latin America is beginning to age. Although the region is a long way from the situation of the world's most aged countries, it is forecast to age much more quickly than did the societies that are currently more advanced. These changes are going to take place in economic and institutional contexts where the living standards of more elderly generations will be much less protected than they are now in the more developed countries. Consequently, it is of the greatest importance for the countries in the region to begin assessing the different policy options available so that they can arrive at the decisions and programmes that are most appropriate to their demographic and economic conditions, now and in the near future.

It is often suggested that population ageing is a key underlying cause of the system's financial problems, but examination of the facts shows that this is generally not the case. This paper has demonstrated that population age structures and mortality patterns can have major effects on medium- to long-term developments in pension systems, but that, so far at least, labour market conditions and administrative problems have played a much more decisive role. In the vast majority of the region's countries the greatest effects of population ageing on pension systems still lie ahead, as was discussed in section III of this paper. That section examined trends in a number of pension system indicators relating to the ageing process, taking in the whole range from the younger age structures in Latin American countries today to the age distribution projected for France in the middle of the twenty-first century.

This paper has shown what might be the general trends in pension spending, financial balance, pension debt and the pension system rate of return if conditions in the system, the labour market and the economy remain unchanged. The analysis suggests that, if future ageing scenarios come about with system rules unchanged, the Latin American countries could see their expenditure, and perhaps their deficit levels, rising to meet those of the countries that are currently more advanced. It was seen, though, that it is very difficult to determine what pension liability levels are "sustainable" or "unsustainable", both in general and for particular countries, except in a few rather extreme cases. Rising expenditure, due in part to long-term population ageing, should not be regarded as a harbinger of imminent crisis or bankruptcy, insofar as it reflects a natural reallocation of resources within the life cycle owing to the increase in life expectancy among individuals and cohorts. The same is true in the case of pension liabilities, which naturally tend to be higher in countries with older populations and with maturer systems that have greater coverage. When systems have to be adapted, parametric changes to offset the effects of population ageing may often be enough. If not, reform options need to be evaluated in the light of the numerous possible permutations of public, private and mixed systems, benefit- or contribution-defined systems and funded or unfunded schemes.

The introduction of greater contribution and benefit funding is a type of reform that has been implemented in a number of Latin American countries and is being actively discussed in other regions as well. Sections IV and $\mathrm{V}$ of this paper raised and analysed some of the issues associated with this kind of reform. It was pointed out that, although funding is generally justified on the grounds of its potential to ease pressure on public budgets, improve labour market efficiency and the development of financial markets, raise saving, capital accumulation and growth rates and provide protection against population ageing and fluctuations in the age structure, the theory is not clear-cut as regards these issues.

The empirical data are not conclusive either, except for a few specific aspects. This paper examined one direct effect of switching to a funding system, the need to make the implicit pension debt explicit, and the fiscal costs that this entails. The model used considers the age structure of the population and shows the important role that this plays. It also shows the lesser effect of old-age mortality and the more substantial one of the system's population coverage, labour market factors and other system parameters such as contribution and replacement rates. Countries that are at an intermediate to more advanced stage of ageing and have systems with wide population coverage show high levels of pension debt, which is often greater than their official public debt and even than their annual GDP. For countries whose reforms envision full funding, this 
translates into considerable fiscal transition costs over the 40 years or so that are required to complete the transition from one type of system to the other.

It was also noted that neither the size of the explicit debt nor the amortization schedule are absolute givens, since they can be, and indeed have been, adapted to suit different national situations. The fiscal costs depend on the strategies followed by governments as regards the degree of funding introduced and the way the implicit pension debt is made explicit. Countries have adopted different variants with a view to making the transition costs more bearable, although these sometimes have a negative effect on the welfare of system participants.

Among the different reform options currently being discussed, it is worth mentioning one that involves introducing contribution-defined mechanisms into unfunded systems. This method allows for ("notional") funding of contributions at a rate that matches growth in total wages, providing benefits that are actuarially fair between cohorts without the need to introduce funding. As with funding systems, in this scheme benefits adjust, to a large extent endogenously, to changes in the old-age survival rate and to population ageing. The fact that funding systems are almost always contribution-defined means they can be integrated more easily into the kind of system described. A system of this type is now being introduced in Brazil, and it could be a worthwhile option for other Latin American countries that are facing some of the demographic, political or fiscal constraints analysed here.

APPENDIX 1

The estimates in table $\mathrm{A} 1$ are based on the data given in The cost of social security. Basic tables 1990-1993 (ILO, 1997). The figures for pension expenditure and revenue refer to public- and privatesector old-age, survivors' and invalidity pensions. The table excludes the expenditure rows for family allowances, unemployment benefits, employment injuries and funeral, sickness and maternity expenses. The "transfers to other schemes" column is also excluded.

Generally speaking, the same rows were used for the income calculation, and the "transfers from other schemes" column was excluded.

Given below are the items included and excluded for each country considered. ${ }^{a}$ References to sections and items in the ILO tables referred to have been kept, in case these should need to be consulted.

\begin{tabular}{|c|c|c|}
\hline Country & Expenditure & Income \\
\hline Argentina & 1. Pensions 2. NC pensions & $\begin{array}{l}\text { 1. Pensions } 2 \text {. NC pensions } 3 \text {. Judiciary } 4 \text {. Retention of wages } \\
\text { 5. Own-account work }\end{array}$ \\
\hline Bahamas & 1. Old-age, survivors' and retirement & 1. Old-age, survivors' and retirement \\
\hline Barbados & 1. OASI & 1. Pensions ( 1 to $3-\mathrm{Xs} 2$ and 3 ) \\
\hline Belize & 1. OASI (long term - funeral grant) & 1. OASI (long term - funeral Xs) \\
\hline Bolivia & 1. OASI + 2. c, d, f & 1. OASI + 2. c, d, f \\
\hline Chile & 1. OAS - TTOS & 1. OAS - TFOS \\
\hline Colombia & All - EI - SM - TTOS & All - EI - SM - TTOS \\
\hline Costa Rica & 2. OASI & 2. OASI \\
\hline Cuba & 1. OASI & 1. OASI \\
\hline Dominica & 1. OASI (long term - funeral grant) & 1. OASI (long term - funeral grant Xs) \\
\hline Ecuador & 1. OASI - SM - EI - UN & 1. OASI - SM - EI - UN \\
\hline Grenada & 1. OASI + 5. Public-sector employees & 1. OASI + 5. Public-sector employees \\
\hline Guatemala & 1. OASI & 1. OASI \\
\hline Guyana & $\begin{array}{l}\text { 1.c OASI + 1.a.ii invalidity + 1.a.iii death } \\
\text { + 2. Dependents' fund }\end{array}$ & 1.c OASI + 1.a.ii invalidity + 1.a.iii death +2 . Dependents' fund \\
\hline Jamaica & $\begin{array}{l}\text { I. National insurance - maternity } \\
\text { - funeral grant + III. Public-sector employees }\end{array}$ & $\begin{array}{l}\text { I. National insurance - maternity - funeral grant } \\
+ \text { III. Public-sector employees }\end{array}$ \\
\hline Nicaragua & 1. OASI & 1. OASI \\
\hline Panama & $\begin{array}{l}\text { 1. OASI + 2. Public-sector employees } \\
+4 \text {. Administration }\end{array}$ & 1. OASI +2 . Public-sector employees +4 . Administration \\
\hline Trinidad and Tobago & 1. OASI +2. NC old-age pension & 1. National insurance - funeral grant and SM Xs \\
\hline
\end{tabular}

a The abbreviations used are as follows:

$\begin{array}{llll}\text { EI } & =\text { employment injuries } & \text { OASI }=\text { Old-age, survivors' and invalidity } & \text { TTOS }=\text { Transfers to other schemes } \\ \text { NC }=\text { Non-contributory } & \text { SM }=\text { Sickness and maternity } & \text { UN }=\text { Unemployment } \\ \text { OAS }=\text { Old-age and survivors' } & \text { TFOS }=\text { Transfers from other schemes } & \text { Xs }=\text { Expenditure }\end{array}$


TABLE A.1

Data and estimates of Social Security expenditures and financial balance, based on ILO (1997) The Cost of Social Security, 1990-1993

\begin{tabular}{|c|c|c|c|c|c|c|c|c|c|c|c|c|c|}
\hline \multirow[b]{3}{*}{ Country } & \multirow[b]{3}{*}{$\begin{array}{l}\text { Proportion } \\
60+(1990)\end{array}$} & \multirow[b]{3}{*}{$\begin{array}{l}\text { Dependency } \\
\text { ratio (1990) }\end{array}$} & \multirow[b]{3}{*}{ Year } & \multicolumn{6}{|c|}{$\begin{array}{l}\text { A. Basic estimate, including } \\
\text { State contribution } \\
\text { Data in } \% \text { of GDP }\end{array}$} & \multicolumn{4}{|c|}{$\begin{array}{l}\text { B. Estimate excluding } \\
\text { State contribution } \\
\text { Data in } \% \text { of GDP }\end{array}$} \\
\hline & & & & \multicolumn{2}{|c|}{ Expenditure } & \multicolumn{2}{|c|}{ Revenue } & \multicolumn{2}{|c|}{ Balance } & \multicolumn{2}{|c|}{ Revenue } & \multicolumn{2}{|c|}{ Balance } \\
\hline & & & & Pensions & Total & Pensions & Total & Pensions & Total & Pensions & Total & Pensions & Total \\
\hline Barbados & 0.15 & 0.30 & 1992 & 2.48 & 5.23 & 3.86 & 8.21 & 1.38 & 2.98 & 3.86 & 8.21 & 1.38 & 2.98 \\
\hline Argentina & 0.13 & 0.27 & 1992 & 4.41 & 4.78 & 4.71 & 5.28 & 0.30 & 0.50 & 4.52 & 5.09 & 0.11 & 0.31 \\
\hline Dominica & 0.12 & 0.23 & 1993 & 1.42 & 2.66 & 2.78 & 4.51 & 1.36 & 1.85 & 2.70 & 4.51 & 1.28 & 1.85 \\
\hline Jamaica & 0.09 & 0.21 & 1991 & 0.66 & 1.05 & 1.39 & 1.72 & 0.73 & 0.67 & 1.39 & 1.72 & 0.73 & 0.67 \\
\hline Cuba & 0.12 & 0.21 & 1991 & 8.40 & 18.00 & 8.40 & 18.00 & 0.00 & 0.00 & 4.85 & 6.50 & -3.55 & -11.50 \\
\hline Grenada & 0.09 & 0.21 & 1993 & 2.23 & 2.66 & 4.14 & 4.83 & 1.91 & 2.17 & 4.14 & 4.83 & 1.91 & 2.17 \\
\hline Chile* & 0.09 & 0.18 & 1993 & 6.89 & 22.67 & 8.91 & 34.15 & 2.02 & 11.48 & 3.91 & 16.25 & -2.98 & -6.42 \\
\hline Trini\&Toba & 0.08 & 0.17 & 1991 & 0.64 & 0.95 & 1.50 & 1.54 & 0.86 & 0.59 & 1.50 & 1.54 & 0.86 & 0.59 \\
\hline Panama & 0.07 & 0.16 & 1990 & 5.76 & 9.31 & 6.01 & 10.43 & 0.25 & 1.12 & 5.66 & 10.08 & -0.10 & 0.77 \\
\hline Belize & 0.06 & 0.16 & 1992 & 0.24 & 1.14 & 1.38 & 2.65 & 1.14 & 1.51 & 1.38 & 2.65 & 1.14 & 1.51 \\
\hline Ecuador & 0.06 & 0.14 & 1991 & 1.85 & 1.95 & 2.39 & 2.93 & 0.54 & 0.98 & 2.13 & 2.67 & 0.28 & 0.72 \\
\hline Bolivia & 0.06 & 0.14 & 1992 & 1.72 & 1.83 & 2.01 & 2.23 & 0.29 & 0.40 & 1.94 & 2.16 & 0.22 & 0.33 \\
\hline Colombia & 0.06 & 0.13 & 1992 & 3.26 & 4.36 & 3.92 & 5.18 & 0.66 & 0.82 & 3.88 & 5.14 & 0.62 & 0.78 \\
\hline Costa Rica & 0.06 & 0.13 & 1993 & 1.92 & 7.65 & 2.26 & 8.91 & 0.34 & 1.26 & 2.19 & 8.08 & 0.27 & 0.43 \\
\hline Bahamas & 0.07 & 0.13 & 1992 & 1.72 & 2.32 & 2.80 & 3.43 & 1.08 & 1.11 & 2.67 & 3.30 & 0.95 & 0.98 \\
\hline Guatemala & 0.05 & 0.13 & 1993 & 0.28 & 1.05 & 0.49 & 1.35 & 0.21 & 0.30 & 0.49 & 1.35 & 0.21 & 0.30 \\
\hline Guyana & 0.06 & 0.13 & 1992 & 1.05 & 1.52 & 1.77 & 2.26 & 0.72 & 0.74 & 1.77 & 2.26 & 0.72 & 0.74 \\
\hline Nicaragua & 0.04 & 0.11 & 1992 & 0.22 & 0.50 & 0.22 & 0.53 & 0.00 & 0.03 & 0.21 & 0.47 & -0.01 & -0.03 \\
\hline Average & 0.08 & 0.17 & & 2.51 & 4.98 & 3.27 & 6.56 & 0.77 & 1.58 & 2.73 & 4.82 & 0.22 & -0.16 \\
\hline
\end{tabular}

Source: Author's estimates, based on ILO (1997) The Cost of Social Security 1990-1993, Basic Tables. Demographic indicators are based on CELADE (1999) population estimates.

* "Income from capital" was excluded in both the A and B estimates, for comparability with the other countries that had not started their funded pillars by 1990-1993. 
APPENDIX 2

\section{Model equations}

The following set of equations are used in the paper to study the relationship between a standard ageing index in the analysis of pension systems, the old age dependency ratio $(d)$, i.e., the ratio of the retirement-age to the working-age population, and selected pension system indicators. The equations are based on the assumption that the contribution rate $(c)$, the replacement rate $(r)$ and the ratio of covered workers to the waged work force $(k)$ stay constant over time in the country of interest. Assuming additionally that pensions are calculated as a proportion of real wages, it follows that:

1. Pension system expenditure (E), expressed as a fraction of annual GDP $(Y)$ is:

$$
E=r \cdot s \cdot k \cdot d
$$

where $s$ is the share of the wage mass in GDP.

2. Since system revenue from contributions is $C=c \cdot s \cdot k$, the system's financial balance $(C-E)$, expressed as a ratio to GDP is:

$$
F i=s \cdot k \cdot(c-r d)
$$

and the balance as a fraction of revenue is:

$$
F_{i i}=1-\left(\frac{r}{c}\right) d
$$

3. The implicit pension debt (see Bravo and Uthoff, 1999) is given by:

$$
D=s k\left(c A_{a}+r d A_{r}\right)
$$

where $A_{a}$ is the discounted average number of years of contribution by the economically active at a given moment in time, and $A_{r}$ is the discounted average expected lifetime of all those in retirement ages at the given moment in time.

4. The pension system's implicit rate of return $(\rho)$, when the system rules are fixed throughout the cohort's adult lifetime (Bravo, 1996, p. 126), can be written as:

$$
\rho_{i}=\frac{1}{\left(A_{R}-A_{W}\right)}\left[\ln \left(\frac{r}{c}\right)+\ln \left(\frac{L R}{L W}\right)\right]+\sigma
$$

where $A_{R}$ is the mean age at retirement, $A_{W}$ the mean working age, $\mathrm{LR}$ is the average number of years lived in retirement, $L W$ the number of working years lived by the individual or cohort of interest, and $\sigma$ is the growth rate of wages. When the financial equilibrium rule holds (Bravo, 1996, p. 127), then

$$
\rho_{i}=\frac{\ln \left(\frac{L R}{L W}\right)-\ln (d)}{\left(A_{R}-A_{W}\right)}+\sigma
$$

\section{Bibliography}

Arenas, A. (2000): El sistema de pensiones en Chile: resultados y desafios pendientes, Santiago, Chile, Economic Commission for Latin America and the Caribbean (ECLAC).

Arrau, P. (1991): La reforma previsional chilena y su financiamiento durante la transición, Colección estudios CIEPLAN, No. 32, Santiago, Chile, Economic Research Corporation for Latin America (CIEPLAN).

(1994): Fondo de pensiones y desarrollo del mercado de capitales en Chile: 1980-1993, Financiamiento del desarrollo series, No. 19, Santiago, Chile, ECLAC.

Auerbach, A. and J. Kotlikoff (1987): Dynamic Fiscal Policy, Cambridge, Massachusetts, Cambridge University Press.

Baldacci, E. and D. Tuzi (1999): Effects of labour market changes on the sustainability of the Italian pension system, Âge, génération et activité: Vers un nouveau contrat social? Proceedings of the lères Rencontres Sauvy, Paris, National Institute of Demographic Studies, December.

Blanchet, D. (1990): Retraites par capitalisation et par répartition selon le contexte démographique: quelques résultats comparatifs, Annales d'économie et de statistique, No. 18,

(1998): Le débat repartition-capitalisation: un état des lieux, Retraites et épargne, Paris, Conseil d'Analyse Économique.

Bravo, J. (1992): Visiones teóricas de la transición de la fecundidad en América Latina. ¿Qué relevancia tiene un enfoque difusionista?, Notas de población, year 20, No. 56, Santiago, Chile, Latin American Demographic Centre (CELADE).

(1996): La tasa de retorno de los sistemas de pensiones de reparto, Estudios de economía, vol. 23, No. 1, Santiago, Chile, University of Chile, Faculty of Economics and Management Sciences, Department of Economics, June.

(1999): Envejecimiento de la población y responsabilidades fiscales hacia los sistemas de pensiones en América Latina, Seminario Responsabilidades Fiscales en Sistemas de Previsión, Santiago, Chile, ECLAC, 2-3 September.

Bravo, J. and A. Uthoff (1999): Transitional Fiscal Costs and Demographic Factors in Shifting from Unfunded to Funded Pensions in Latin America, Financiamiento del desarrollo series, No. 88, Santiago, Chile, ECLAC.

Brazil, Government (1998): Custos de transição para um sistema de capitalização individual, Informe de Previdência Social, vol. 10, No. 2, Brasilia, February.

Calot, G. and J.C. Chesnais (1997): Le vieillissement démographique dans l'Union européenne à l'horizon 2050: une étude d'impact, Travaux et recherches de prospective, No. 6, Paris, Commissariat Général du Plan, October.

Chackiel, J. (2000): El envejecimiento de la población latinoamericana, Encuentro latinoamericano y caribeño 
sobre las personas de edad, Santiago, Chile, ECLAC, August.

Chand, S. and A. Jaeger (1996): Ageing Populations and Public Pension Schemes, Occasional Paper, No. 147, Washington, D.C., International Monetary Fund (IMF).

Chauveau, T. and R. Loufir (1995): L'avenir des régimes publics de retraite dans les pays du G7, Revue de l'OFCE, No. 52, Paris, Observatoire Français des Conjonctures Économiques (OFCE), January.

Cifuentes, R. (1995): Reforma de los sistemas previsionales: aspectos macroeconómicos, Cuadernos de economía, year 32, No. 96, Santiago, Chile, Catholic University of Chile.

Conseil d'Analyse Économique (1998): Retraites et épargne, Paris, La Documentation Française.

Conte-Grand, A. (1995): Reparto o capitalización-gestión pública o privada: aporte para las discusiones en materia de seguridad social, Working document, No. 24, Santiago, Chile, International Labour Organization (ILO).

Cosio-Zavala, M. (1996): The demographic transition in Latin America and Europe, J.M. Guzmán and others (eds.), The Fertility Transition in Latin America, Oxford, U.K., Clarendon Press.

Cox, A. (1999): Pensions projections for Chilean men and women: Estimates from social security contributions, World Bank Research Project on Gender and Social Security, Washington, D.C., World Bank.

Dinh, Q. (1995): Projection de population totale pour la France Metropolitaine, base RP90, horizons 1990-2050, Paris, National Institute of Statistics and Economic Studies.

Dumont, J.P. (1998): Les systèmes de protection sociale en Europe, Paris, Fédération Mutualiste Parisienne (FMP), Mutualité Francilienne.

ECLAC (1998): The Fiscal Covenant. Strengths, weaknesses, challenges, LC/G.2024, Santiago, Chile, April.

ECLAC/CELADE (1996): Impacto de las tendencias demográficas sobre los sectores sociales en América Latina: contribución al diseño de políticas y programas, E-CELADE series, No. 45, Santiago, Chile.

(1998): Latin America: population projections, 19702050, Demographic Bulletin, year 31, No. 62, Santiago, Chile.

(1999): Latin America: Economically active population 1980-2025, Demographic Bulletin, No. 64, Santiago, Chile.

El Mercurio (1997): Pulso latinoamericano, Santiago, Chile, 27 March.

Franco, D. (1995): Pension Liabilities: Their Use and Misuse in the Assessment of Fiscal Policies, Economic Papers, No. 110, Brussels, Luxembourg, European Commission, May.

Gokhale, J. (1995): Demographic changes, generational accounts and national saving in the United States, paper presented at the Conference on Intergenerational Economic Relations and Demographic Change, Honolulu, Hawaii, International Union for the Scientific Study of Population (IUSSP)/East-West Center (EWC), September.

Guzmán, J.M. (1996): Social change and fertility decline in Latin America, J.M. Guzmán and others (eds.), The
Fertility Transition in Latin America, Oxford, U.K., Clarendon Press.

Holzmann, R. (1997a): On Economic Benefits and Fiscal Requirements of Moving from Unfunded to Funded Pensions, Financiamiento del desarrollo series, No. 48, Santiago, Chile, ECLAC.

(1999): Comments to "Rethinking pension reform: Ten myths about social security", by P. Orszag and J. Stiglitz, paper presented at the Conference on New Ideas about Old Age Security, Washington, D.C., World Bank, September.

ILO (1997): The cost of social security, Basic Tables 1990 1993, http:/www-ilo-mirror.who.or.jp/public/english/ $110 \mathrm{secso} / \mathrm{css} /$.

Kinsella, K. and Y. Gist (1995): Older Workers, Retirement and Pensions: A Comparative International Chartbook, Washington, D.C., U.S. Department of Commerce, Bureau of the Census/U.S. Department of Health and Human Services, National Institute on Ageing.

Le Monde-Économie (1999): Paris, 19 January.

Lee, R. (1995): A Trans-cultural perspective of intergenerational transfers, paper presented at the Conference on Intergenerational Economic Relations and Demographic Change, Honolulu, Hawaii, IUSSP/EWC, September.

Leibfritz, W. and D. Roseveare (1995): Ageing populations and government budgets, The OECD Observer, No. 197, Paris, Organisation for Economic Co-operation and Development (OECD).

Mesa-Lago, C. (1985): Social Security in Latin America, Cuadernos de la CEPAL series, No. 85, Santiago, Chile, ECLAC.

(1991): Social Security and Prospects for Equity in Latin America, World Bank discussion papers, No. 140, Washington, D.C., World Bank.

(1994): La reforma de la seguridad social y las pensiones en América Latina: importancia y evaluación de las alternativas de privatización, Reformas de política pública series, No. 28, Santiago, Chile, ECLAC.

(2000): Estudio comparativo de los costos fiscales en la transición de ocho reformas de pensiones en América Latina, Financiamiento del desarrollo series, No. 93, Santiago, Chile, EClaC.

Meslé, F. and J. Vallin (1998): Tables de mortalité du moment 1806-2100: sexe féminin, sexe masculin, sexes réunis, Paris, National Institute of Demographic Studies.

Orszag, P. and J. Stiglitz (1999): Rethinking pension reform: Ten myths about social security, paper presented at the Conference on New Ideas about Old Age Security, Washington, D.C., World Bank, 14-15 September.

Pinheiro, V. and S. Vieira (2000): Reforma previsional en Brasil. La nueva regla para el cálculo de los beneficios, Financiamiento del desarrollo series, No. 97, Santiago, Chile, ECLAC.

Queisser, M. (1998): The second-generation pension reforms in Latin America, OECD working paper, Paris, OECD.

Reynaud, E. (coord.) (1998): Les retraites dans l'Union européenne: adaptation aux évolutions économiques et sociales, Paris, L'Hartman.

Rofman, R. (1997): Modelling transition costs in social security reforms, paper presented at the International 
Population Conference, Beijing 1997, session I.29: Intergenerational Transfers and Population Ageing, Belgium, IUSSP.

Roseveare, D. and others (1996): Ageing Populations, Pension Systems and Government Budgets: Simulations for 20 OECD Countries, OECD Economics Department working papers, No. 168, Paris, OECD.

Sauvy. A. (1953): L'Europe et sa population, Paris, National Institute of Demographic Studies.

Schmidt-Hebbel, K. (1995): La reforma pensional colombiana: efectos fiscales y macroeconómicos, Bogotá, Bogotá, Stock Exchange.

(1997): Pension Reform, Informal Markets and Long-Term Income and Welfare, Working document, No. 4, Santiago, Chile, Central Bank of Chile.

Thompson, L. (1999): Pension reform in industrialized countries, paper presented at the Latin American and Caribbean Symposium on Older Persons, Santiago, Chile, ECLAC, 8-10 September.

Thogersen, O. (1998): A note on intergenerational risk sharing and the design of pay-as-you-go pension programs, Population Economics, vol. 11, No. 3, Berlin, Springer-Verlag.

United Nations (1998): World Population Prospects: the 1996 Revision, New York, Department of Economic and Social Affairs.

(1999): World Population Prospects: the 1998 Revision. Sex and Age, New York, Department of Economic and Social Affairs.

Uthoff, A. (1997): Pension system reforms, the capital market and saving, CEPAL Review, No. 63, LC/G.1986-P, Santiago, Chile, ECLAC

(1999): Perfil de responsabilidades fiscales de una eventual sustitución hacia un sistema de capitalización individual en Brasil, paper presented at the Responsabilidades Fiscales en Sistemas de Previsión Seminar, Santiago, Chile, ECLAC, 2-3 September.

Uthoff, A. and J. Bravo (1998): Deuda previsional y privatización de los sistemas de pensiones, $X$ Seminario Regional de Política Fiscal: Compilación de Documentos, Santiago, Chile, ECLAC, 26-28 January.

Valdés-Prieto, S. (ed.) (1997): The Economics of Pensions: Principles, Policies and International Experience, London, Cambridge University Press.

Valdés-Prieto, S. (1999): El tamaño de las comisiones de las AFP: comparación internacional, Santiago, Chile, Catholic University of Chile.

Van der Noord and Herd (1993): Pension Liabilities in Seven Major Economies, Working paper, No. 142, Paris, OECD.

(1994): Estimating pension liabilities: A methodological framework, OECD Economic Studies, No. 23, Paris, OECD.

Vernière, L. (1997a): La mesure et l'interpretation de l'équivalent patrimonial des droits à la retraite, Questions retraite, No. 4, Paris, Caisse de Dépots et Consignations, Branche Retraites..

(1997b): Une évaluation de l'équivalent patrimonial des droits détenu par les retraités en France, Questions retraite, $\mathrm{N}^{\circ} 5$, Paris, Caisse de Dépôts et Consignations, Branche Retraites.

Villa, M. and L. Rivadeneira (2000): El proceso de envejecimiento de la población en América Latina y el Caribe: una expresión de la transición demográfica, Encuentro Latinoamericano y Caribeño sobre las Personas de Edad, Santiago, Chile, ECLAC, August.

World Bank (1994): Averting the Old Age Crisis. Policy Research Report, Oxford, U.K., Oxford University Press. 